\title{
CÔNG NGHỆ QUÉT SƯỜN SIDE SCAN SONAR VÀ ỨNG DỤNG TRONG KHẢO SÁT, THĂM DÒ ĐÁY BIỂN
}

\author{
DƯƠNG VÂN PHONG ${ }^{(1)}$, KHƯƠNG VĂN LONG ${ }^{(2)}$ \\ (1)Trường Đại học Mỏ - Địa chất \\ ${ }^{(2)}$ Đoàn Đo đạc Biên vẽ hải đồ và Nghiên cứu biển
}

\section{Tóm tắt:}

Khảo sát thăm dò đáy biển là một lĩnh vực rất rộng, đòi hỏi đầu tư rất lớn về phương tiện, trang bi và con người. Để thu thập được các yếu tố trong nước biển, bề mặt đáy biển và phía dưới bề mặt đáy biển chúng ta đã có những trang bị rất hiện đại như các loại thiết bị thu thập dữ liệu các yếu tố hải dương, hệ thống đo sâu đa tia, hệ thống quét biển Side Scan Sonar, hệ thống khảo sát từ trường, địa chấn, trọng lực,... Mỗi hệ thống đều có chức năng, nguyên lý hoạt động và mục đích sử dụng khác nhau. Bài báo này giới thiệu về hệ thống quét biển Side Scan Sonar và ưng dụng trong khảo sát, thăm dò đáy biển.

\section{1. Đặt vấn đề}

Hệ thống thủy âm quét sườn Side Scan Sonar (SSS) hoạt động dựa trên nguyên lý của phương pháp đo sâu hồi âm. Các tín hiệu sóng âm được phát xuống bề mặt đáy biển và nhận được tín hiệu phản xạ (tín hiệu tán xạ ngược). Sử dụng các phần mềm kèm theo thiết bị để phân tích, giải đoán phục vụ xác định bề mặt đáy biển, các đối tượng, các địa vật và các thông tin khác. Sau khi được số hóa (digital) ảnh thủy âm có thể được chỉnh sửa và tích hợp các thông tin về tọa độ và độ sâu. Nguyên lý chung của thủy âm quét sườn sử dụng trong thành lập bản đồ địa hình đáy biển là kết hợp giữa số liệu đo sâu và phân tích, giải đoán, xử lý ảnh quét địa hình, địa vật thu được sau khi khảo sát.

Tín hiệu phản xạ trở lại từ đáy biển được tiếp nhận bởi các đầu thu sóng âm trong khoảng thời gian rất ngắn (trong phạm vi mili giây), được khuếch đại và được truyền theo cáp đến thiết bị phân tích và xử lý. Máy ghi (bộ phận chuyển đổi) tiếp nhận tín hiệu, số hóa, tính toán các vị trí thích hợp cho các điểm ảnh, ghi lại từng pixel sau đó lưu lại để xử lý, giải đoán phục vụ các yêu cầu cao hơn.

\section{Cấu trúc và nguyên lý hoạt động}

Hệ thống SSS được thiết kế để cung cấp hình ảnh của bề mặt đáy biển, là một công cụ rất hữu ích trong việc tìm kiếm các mục tiêu như xác tàu đắm, các đường ống ngầm, đường cáp, xác định tính chất bề mặt đáy biển,... Hệ thống SSS bao gồm: thiết bị thu phát tín hiệu sensor dưới nước (cá kéo), thiết bị kết nối và thiết bị hiển thị, xử lý, lưu trữ dữ liệu (hình 1),

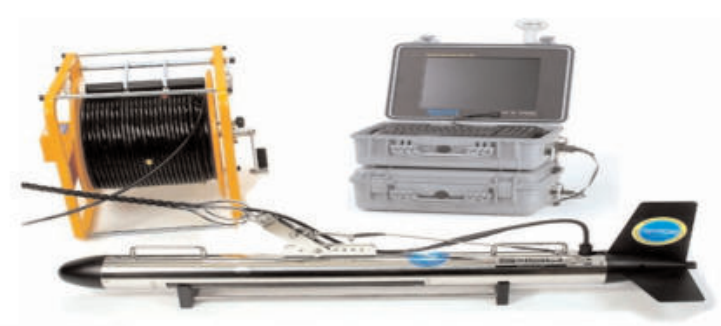

Hình 1: Thiết bị quét sườn Side Scan Sonar CMax CM2

Để xác định hiệu suất hoạt động của hệ thống thiết bị SSS, chúng ta nghiên cứu một số yếu tố sau: 
Hệ thống SSS phát sóng âm truyền trong môi trường nước tác động lên bề mặt đáy biển hoặc các vật thể nằm trên bề mặt đáy biển và phản hồi trở lại. Khoảng cách mà sóng âm truyền đi từ bề mặt bộ chuyển đổi (tranducer) đến mục tiêu được gọi là khoảng cách nghiêng (slant- range), còn khoảng cách tính từ mục tiêu đến tia thẳng đứng (ground - range) là khoảng cách ngang. Góc giữa tia sóng âm và bề mặt đáy biển (hoặc mục tiêu) gọi là góc nghiêng

Sóng âm sau khi đến mục tiêu sẽ phản hồi trở lại và được thu về bởi đầu thu trong một thời gian rất ngắn, được khuyếch đại và truyền tới thiết bị xử lý để xử lý tín hiệu phản hồi.

Hệ thống phát sóng âm truyền đi trong nước dưới dạng xung, số xung được phát trong một giây gọi là tần số xung lặp lại (RPF), quãng thời gian xung phát đi và thu về phụ thuộc vào dải đo lựa chọn.

Vận tốc truyền âm trong nước biển xấp xỉ $1500 \mathrm{~m} / \mathrm{s}$, vận tốc truyền âm phụ thuộc vào độ muối, độ sâu và nhiệt độ của nước biển nên ở các khu vực khác nhau, thời gian đo và độ sâu khác nhau, tốc độ truyền âm cũng sẽ khác nhau.

Tín hiệu âm thanh được phát đi đến mục tiêu không chỉ do nguồn phát chủ động của thiết bị mà còn có các tín hiệu âm nhiễu khác phát ra bởi các nguồn khác nhau như: động đất, sinh vật biển, máy tàu và âm thanh phát ra do chân vịt, sóng bề mặt.... chất lượng tín hiệu âm thanh thu về được xác định bằng tỷ lệ nhiễu tín hiệu $(\mathrm{S} / \mathrm{N})$ :

Tỷ số tín hiệu so với nhiễu $(\mathrm{S} / \mathrm{N})=$ Độ lớn tín hiệu phản hồi/ Độ lớn nhiễu thu được.

Tỷ số tín hiệu so với nhiễu $(\mathrm{S} / \mathrm{N})$ phải đủ lớn để thiết bị thu nhận biết được tín hiệu phản hồi do nguồn phát chủ động.

Đối với SSS thì hiệu suất là một đặc tính của hệ thống và bị ảnh hưởng bởi các yếu tố trong nước biển và cấu trúc vật chất của mục tiêu. Để xác định tính ảnh hưởng của các yếu tố này ta sử dụng phương trình sonar chủ động dưới dạng sau [1]:

$$
\mathrm{SE}=\mathrm{SL}-\mathrm{TL}-(\mathrm{NL}-\mathrm{DI})+\mathrm{TS}-\mathrm{DT} \text {, trong }
$$
đó:

SE (Signal Excess) là độ lớn của tín hiệu phản hồi từ mục tiêu, yếu tố này phải lớn hơn mức nhỏ nhất yêu cầu để phát hiện được mục tiêu.

SL (Source Level) là độ lớn của năng lượng sóng âm được phát đi bởi đầu phát.

DT (Detection Threshold) là mức nhỏ nhất của năng lượng sóng âm đủ để phát hiện mục tiêu.

TL (Transmission loss) là độ suy giảm cường độ sóng âm theo độ tăng của dải phát tín hiệu. Có hai nguyên nhân gây ra suy giảm cường độ sóng âm trong quá trình thu phát là do bị hấp thụ và bị phân tán trong môi trường nước. Khi sóng âm phát đi càng xa nguồn thu thì càng bị phân tán nhiều (hình 2).

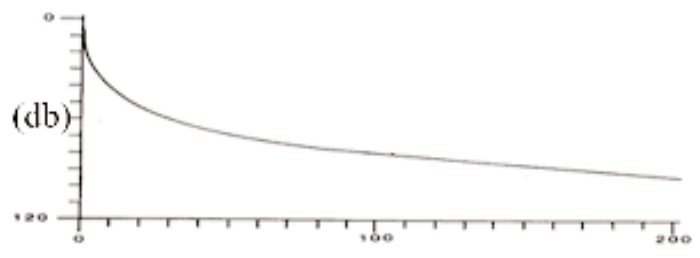

Dải quét

Hình 2: Biểu đồ quan hệ giữa dải quét và năng lượng phân tán của tín hiệu

Cường độ sóng âm bị hấp thụ bởi môi trường mà sóng truyền qua, tốc độ hấp thụ phụ thuộc tần số của xung phát đi và loại môi trường mà sóng âm đi qua. Tần số càng cao thì độ hấp thụ càng lớn. Đây là một trong các yếu tố quan trọng để cài đặt thông số hoạt động trong quá trình khai thác thiết bị (hình 3). 


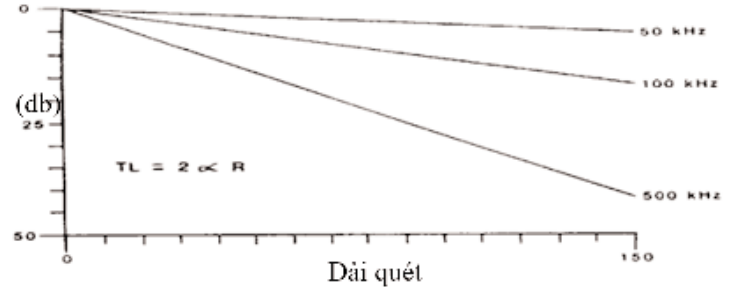

Hình 3: Đồ thị quan hệ giữa dải quét và năng lượng bị hấp thụ

NL (Noise Level) là độ ồn gây ra bởi môi trường tự nhiên hoặc do con người tạo nên. Độ ồn gây ra bởi môi trường do ảnh hưởng các yếu tố sóng biển, bọt khí, nhiễu loạn trong nước, ảnh hưởng do mưa, ngoài ra còn ảnh hưởng bởi các sinh vật biển trong nước như cá heo,... Độ ồn do con người gây ra như hoạt động của tàu (hoạt động của máy chính, máy điện, chân vịt,...).

DI (Directivity Index) là độ giảm thiểu độ ồn của thiết bị vì chiều rộng chùm tia được giới hạn

TS (Target Strength) là cường độ phản hồi sóng âm của mục tiêu, phụ thuộc vào tính chất, hình dáng, kích thước, hướng của mục tiêu và mức độ làm suy giảm âm thanh của mục tiêu.

Độ suy giảm âm thanh của mục tiêu thay đổi theo tính chất của vật chất tạo nên mục tiêu đó. Ví dụ: túi khí ở trong nước có độ phản xạ rất tốt, thảm thực vật có độ phản xạ kém, còn sắt có độ phản xạ tốt nhất.

Hệ thống SSS phát ra chùm tia mỗi bên, chùm tia hẹp theo phương ngang (khoảng 1 degree) và rộng theo phương thẳng đứng (khoản 50 degree). Điều này phụ thuộc vào hình dáng của đầu phát (transducer), bao gồm nhiều các đầu phát nhỏ tạo thành và chiều dài của đầu phát. Đầu phát càng dài thì chùm tia càng hẹp và ngược lại. Ngoài ra còn phụ thuộc vào tần số phát, tần số càng cao thì chùm tia càng hẹp và ngược lại (hình 4).

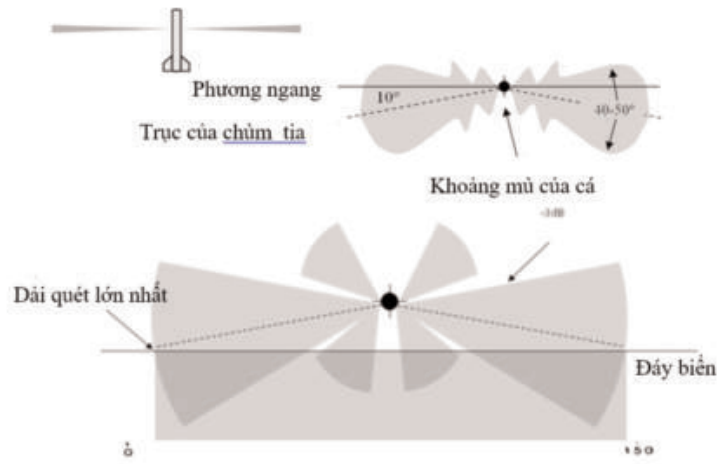

Hình 4: Một số dạng chùm tia của SSS

Trong quá trình khai thác hệ thống SSS có rất nhiều thao tác phải được tính toán cẩn thận và thực hiện nghiêm ngặt theo quy trình quy định để đảm bảo chất lượng kết quả dữ liệu thu được và an toàn cho hệ thống. Chẳng hạn độ cao tối ưu của cá kéo phụ thuộc vào khoảng cách nghiêng lớn nhất của chùm tia và được lựa chọn xấp xỉ bằng $10 \%$ giải quét để đảm bảo thu được hình ảnh rõ nét, chi tiết và đầy đủ. Trong trường hợp độ cao cá quá cao thì diện tích trùm phủ có hiệu quả của chùm tia sẽ giảm, ngược lại khi độ cao của cá quá thấp thì sẽ rất nguy hiểm cho cá kéo, do dễ bị va chạm với các chướng ngại hoặc đáy biển, đồng thời khu vực đáy biển hoặc các vật thể nhỏ trên đáy biển nằm sau bóng của vật thể lớn phía trước sẽ không thể phát hiện được.

Vị trí của mục tiêu so với cá kéo, địa hình khảo sát cũng ảnh rất nhiều đến kết quả thu được. Về nguyên tắc chung, vị trí mục tiêu phải gần với cá kéo nhưng không nằm trong khoảng mù của cá kéo. Khoảng mù là diện tích nằm ngay dưới cá kéo, có chiều rộng gần xấp xỉ với hai lần độ cao của cá.

Khả năng, chất lượng phát hiện, tính toán kích thước mục tiêu phụ thuộc vào số lần xung tác động lên mục tiêu. Càng nhiều xung tác động thì mục tiêu càng dễ phát hiện. Một vật được phát hiện khi có ít nhất 5 xung tác động lên. Số lượng xung tác động lên một vật phụ thuộc vào tần số xung lặp 
(PRF) và tốc độ của cá kéo.

Trong quá trình khảo sát phát hiện chướng ngại đòi hỏi phải sử dụng hệ thống có tần số phù hợp. Tần số càng cao cho kết quả thu được càng chi tiết, nhưng lại hạn chế về chiều rộng dải quét. Ngoài ra phải điều chỉnh tốc độ tàu, dải quét phù hợp và phải ước lượng được độ lớn của mục tiêu cần phát hiện, các yếu tố này liên hệ với nhau theo công thức [2]:

$$
v \quad c \times\left[\begin{array}{c}
I+\left(\begin{array}{c}
R_{v} \times 13 A \times \\
780
\end{array}\right) \\
(n-I) \times R_{m}
\end{array}\right] \times 0.971922246
$$

Trong đó: v là vận tốc của cá kéo; c là tốc độ âm thanh trong nước; $L$ là chiều dài của mục tiêu (theo hướng vuông góc với tia phát); Rs là dải quét bé nhất để số lần xung tối thiểu tác động lên mục tiêu (ít nhất 5 lần); $\mathrm{BA}$ là góc phát của chùm tia; $\mathrm{n}$ là số lần xung tác động lên mục tiêu và $R m$ là thang tỷ lệ.

Trên cơ sở tính toán tốc độ của cá trong quá trình xử lý sẽ hiệu chỉnh được độ biến dạng hình ảnh, đồng thời dựa vào độ lớn, độ sáng, hình dáng bóng của mục tiêu trên bề mặt đáy biển. Sau khi đã hiệu chỉnh các nguồn sai số, chúng ta biết được hình dáng, tính chất của bề mặt cũng như kích thước của mục tiêu nằm trên bề mặt đáy biển và các mục tiêu nằm lơ lửng trong nước (hình 5).
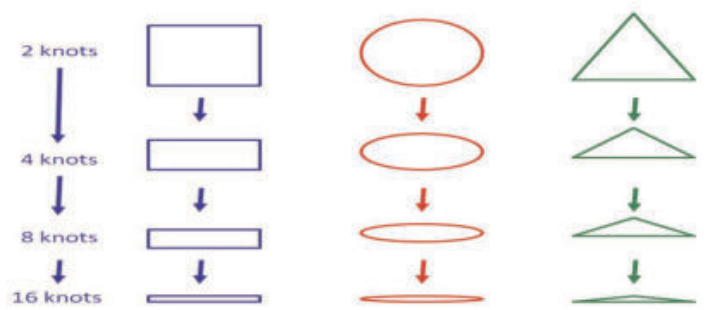

Hình 5: Ảnh hưởng của tốc độ kéo đến hình dáng vật thể

\section{Phương pháp định vị}

Vị trí các tất cả các đối tượng thu thập được bằng hệ thống SSS đều dựa trên tọa độ vị trí của cá kéo. Tọa độ vị trí của cá kéo được xác định từ tọa độ của tàu kéo (được xác định bằng DGPS) theo hai phương pháp:

- Phương pháp định vị thủy âm: Gồm 02 bộ phận. Bộ phận phát tín hiệu được gắn phía dưới đáy tàu, tại vị trí đã được xác định tọa độ; bộ phận thu tín hiệu được gắn trên cá kéo. Dựa vào thời gian, hướng tín hiệu phát đi, thu về để xác định vị trí của bộ phận thu. Phương pháp này cho độ chính xác rất cao.

- Phương pháp hiệu chỉnh chiều dài cáp thả cá kéo (Layback): Dựa vào chiều dài cáp, độ sâu của cá và yếu tố dòng chảy... để xác định vị trí của cá. Phương pháp này có độ chính xác kém hơn định vị thủy âm, đồng thời có thể bỏ sót một số khu vực trong quá trình khảo sát.

\section{Kết quả khảo sát thực địa}

Sử dụng thiết bị Sonar Side Scan CM2 của Hãng C-MAX (Vương quốc Anh), lắp đặt trên tàu nghiên cứu biển "Trần Đại Nghĩa" để khảo sát địa hình đáy biển khu vực biển Bình Thuận và Khánh Hòa. Hệ thống quét biển $\mathrm{CM} 2$ giúp phát hiện và nhận dạng các đối tượng chìm dưới nước thông qua hình ảnh trực tiếp trong quá trình khảo sát kết hợp với kinh nghiệm xử lý, giải đoán ảnh để xác định kích thước của chướng ngại. Các thông số kỹ thuật của $\mathrm{CM} 2$ có thể tham khảo tại [3], [4]. Hệ thống CM2 được tích hợp với thiết bị đo sâu hồi âm đa tia để đo địa hình đáy biển; hệ thống khảo sát từ trường để xác định chất liệu mục tiêu và Hệ thống DGPS (hình 6).

Sử dụng phần mềm MaxView để điều khiển và thu thập dữ liệu quét bề mặt địa hình đáy biển và phần mềm Hypack để xử lý và phân tích hình ảnh. Một số kết quả thu được như sau: 


\section{Nghiên cúu - Úng dụng}

- Tìm kiếm xác tàu đắm tại vùng biển Khánh Hòa (năm 2012; a- mô hình đo sâu đa tia; b- ảnh quét từ thiết bị CM2)
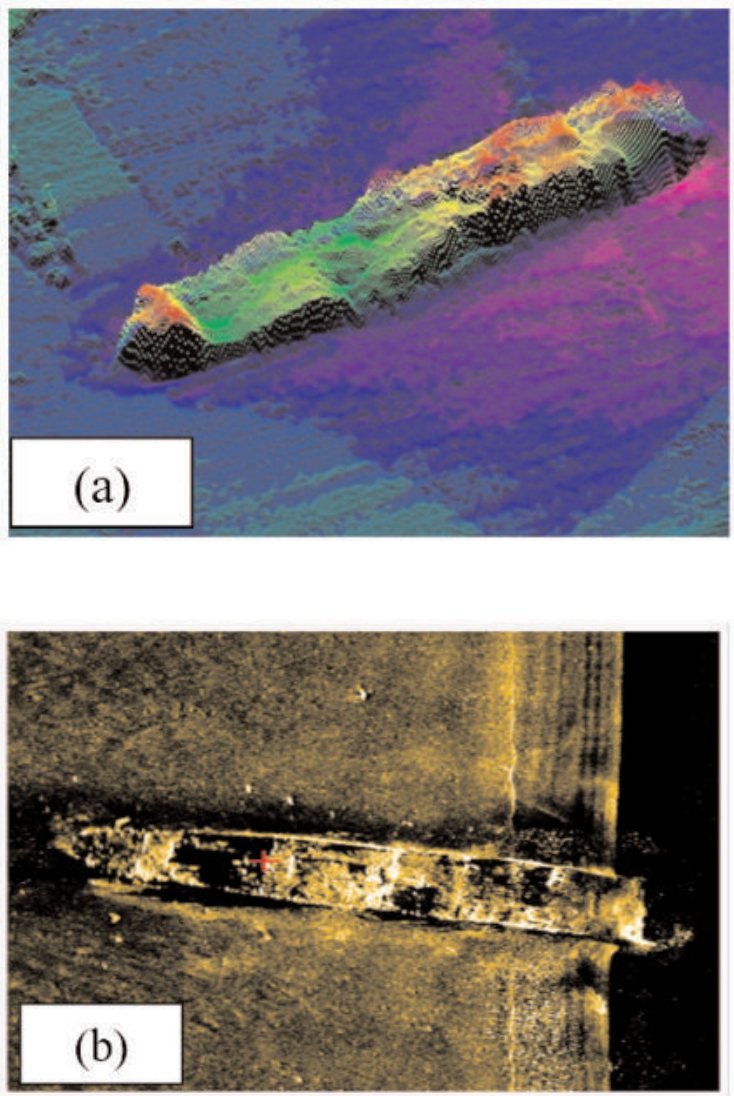

- Khảo sát khu vực máy bay Su 22 bị tai nạn tại biển Bình Thuận.

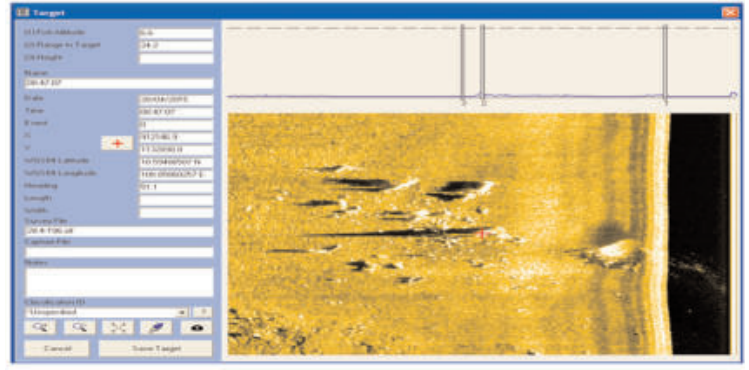

\section{Kết luận}

Kết quả khảo sát thăm dò đáy biển bằng thiết bị Side Scan Sonar CM2 cho thấy Side Scan Sonar là công nghệ hiện đại, cho phép khảo sát, thu thập dữ liệu đáy biển có độ tin cậy cao. Khi tích hợp với thiết bị đo sâu hồi âm đa tia sẽ cho ta một bức tranh toàn diện và chi tiết địa hình đáy biển. Công nghệ Side Scan Sonar sẽ góp phần đắc lực vào công tác điều tra cơ bản tài nguyên môi

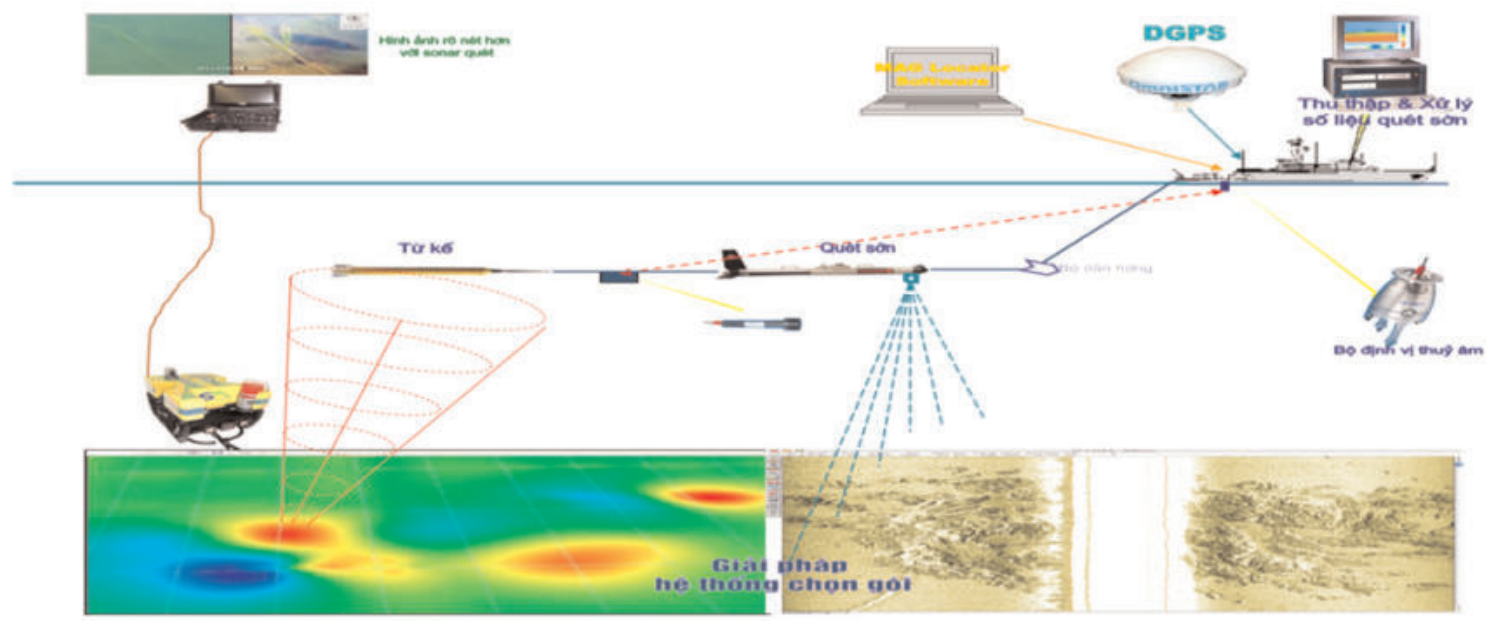

Hình 6: So đồ hệ tích hợp hệ thống quét biển, từ trường và định vị thủy 


\section{Nghiên cúu - Úng dụng}

trường biển, phục vụ phát triển kinh tế xã hội theo hướng biển và đặc biệt là phục vụ cho các nhiệm vụ bảo vệ chủ quyền biển đảo của Tổ quốc với vũ khí, phương tiện ngày càng hiện đại của Quân đội. $O$

\section{Tài liệu tham khảo}

[1]. Quân chủng Hải quân (2017). Cơ sở âm học hải dương thực hành. Tài liệu huấn luyện kỹ thuật.
[2]. Корякин Ю.А., Смирнов С.А., Яковлев Г.В. (2004). Корабельная гидроакустическая техника: состояние и актуальные проблемы. СПб.: ЦНИИ «Морфизприбор».

[3]. http://www.thietbithuydac.com/raquet-side-scan-sonar/cmax-cm2.htm

[4]. http://www.cmaxsonar.com $\bigcirc$

\section{Summary}

\section{Side scan sonar and applications in sea bottom surveying}

Duong Van Phong, Hanoi University of Mining and Geology

Khuong Van Long, Department of Maritime Mapping and Maritime Studies

Seabed exploration is a very broad field, requiring enormous investment in facilities, equipment and people. In order to collect elements in seawater, seafloor and below the surface of the seafloor we have modern equipment such as marine data collection devices, multibeam echosounder, side scan sonar, magnetic field, seismic, gravity surveying systems. Each system has different functions, operating principles and using purposes. This article introduces the side scan sonar and its application in sea bottom surveying. $O$ 